\title{
Aspects of the Inter Professional Learning Process of Medical Students Involved in a Family Health Unit
}

\author{
Valéria Menezes P. Machado1,2, José Lúcio M. Machado²,3, Sonia Regina Pereira dos Santos', \\ Gustavo José Martiniano Porfírio ${ }^{4}$ \\ ${ }^{1}$ Medical School, Sao Paulo City University-UNICID-SP, Sao Paulo, Brazil \\ ${ }^{2}$ Civil Servant Sao Paulo Hospital-IAMSPE, Sao Paulo, Brazil \\ ${ }^{3}$ Department of Surgery, Botucatu Medical School-UNESP, Sao Paulo, Brazil \\ ${ }^{4}$ Medical School, São Caetano do Sul University-USCS-SP, Sao Paulo, Brazil \\ Email: vmmp28@yahoo.com.br, jluciomm@yahoo.com.br, smalkaluyehi@gmail.com, gustavo.porfirio@gmail.com
}

How to cite this paper: Machado, V. M. P., Machado, J. L. M., dos Santos, S. R. P., \& Porfírio, G. J. M. (2017). Aspects of the Inter Professional Learning Process of Medical Students Involved in a Family Health Unit. Creative Education, 8, 2210-2221.

https://doi.org/10.4236/ce.2017.814151

Received: August 23, 2017

Accepted: November 6, 2017

Published: November 9, 2017

Copyright $\odot 2017$ by authors and Scientific Research Publishing Inc. This work is licensed under the Creative Commons Attribution International License (CC BY 4.0).

http://creativecommons.org/licenses/by/4.0/

\begin{abstract}
A new perspective for health completeness, for different knowledges and practices and the development of new dimensions of care needed to work inside multidisciplinary teams in the Sistema Único de Saúde (SUS) led to the search for new forms of training, with the support of Brazilian National Curriculum Guidelines (Brasil. Ministério da Educação-MS, 2001). This study evaluates aspects of the interprofessional way of teaching and integration of students from the medical school at Sao Paulo City University, employing a weekly qualitative analysis evaluation (cards) of students and the half-yearly narratives on practices (2008-2012). The speeches of the students showed positive feelings (95\%) related to practice. The core ideas were "motivation" (50.84\%), "teamwork" and "interprofessional relations" (74\%). The analysis of the narratives identified the "community people" as the most affecting the students, followed by the physician figure (due to their own professional option). The medical care was the activity that mostly involved the students.
\end{abstract}

\section{Keywords}

Interprofessional Learning, Community Learning, Students Representations, Problematization Method

\section{Introduction}

Along to the Sistema Único de Saúde (SUS) construction process, some important changes have occurred in Brazil in the last decades. The Family Health Strategy as a health promoter, considering the persons and their way of life, their 
relationships with family and friends and their social representations demanded that health practice must be developed by team workers (Silva \& Trad, 2005). Different point of views of disease process, comprehensiveness in health care and different knowledge and practices assemblies also led to the development of work in interdisciplinary and interprofessional teams, revealing new dimensions of care for people in their whole complexity.

The aspects of unique health care and the complex individual need call for the development of different approaches, involving a list of skills, beyond the professional performance and cognitive barriers to enable an interprofessional learning. However, this way of learning requests an exercise of integrating curricula in order to expose students to different experts and to an integrated teamwork.

Experiments of curricula integration among medical courses and other health areas are still incipient in our country. The concept of a common axis connecting the different health professions enables further approximation to the Interprofessional Education (IE), which is committed to the skills common to both specific and collaborative professions (Batista, 2012). It is understood that the movement of construction of a collaborative taskforce is essential to the construction of excellent services, in the broadest sense, considering the principles of the SUS, being health professionals trained within the IE parameters (WHO, 2010).

The IE can be understood as an educational proposal in which two or more professional groups learn together shared work skills, as well as the essentials of each one, to improve quality in care (McNair, 2005). This enables the development of different abilities, such as communication talent and criticism to face the challenges, all together leading to the enhancement of job opportunities and benefits of the whole team, with a mutual respect strengthening the ethical principles (Barr, 1998). These abilities are essential for a practice that enables and contributes to comprehensive care within a broader concept of health.

The EI opens up the possibility of the development of interprofessional teamwork and encourages collective solutions to face daily problems of health network, promoting negotiation between the involved actors and increasing their capacity of decision (Batista, 2012).

The IE principles assert themselves especially through collaborative practices. The Framework for Action on Interprofessional Education and Collaborative Practice puts the focus on the importance of an integrated education and practice to improve the performance of health systems, promoting attention to the most qualified and responsive population (WHO, 2010).

Collaborative practice assumes mutual understanding, respect to the specific nature of each profession and learning with the dissimilarities. It enables to learn with, for and about the other and to improve each professional practice through the complementarity of specific skills. Collaborative practice unlocks the integration and actions sharing, which allow better response to the needs of people. 
Considering the aforementioned issues, it is understood as essential both some changes in education and health policies.

The Brazilian National Curriculum Guidelines for medical courses suggests that the students must be placed into meaningful work situations inside public health system, especially in the Family Health Team, whose main axis is the multidisciplinary team working inside the community, considering their individual and collectives necessities (Brasil. Ministério da Educação-MS, 2001). The SUS, while changing their strategies in relation to care, call for a staff with a broader list of skills for their professional activities. Interesting that SUS was able to cause significant impact on strategies on teaching and learning without, however, doing a robust change in the ways of training in the years following its implementation (Ceccim \& Feuerwerker, 2004). Subsequently, the national curricular changes were driven by Public Policies.

The public policies were crucial to reinforce the need for training health professionals under new paradigms able to respond to innovations that were already taking place in SUS working processes. The $11^{\text {th }}$ National Health Conference (Brasil. Ministério da Saúde, 2000) already pointed out the need for “...a human resource policy focused on professionalization in multi professionality..." (Brasil. Ministério da Saúde-MS, 2000).

We need to think in curricula based on dialogue that are flexible and versatile, prone to adjustments and integration, and in line with the government policies (Machado, Machado, \& Vieira, 2012). To recognize health as a right, and act to ensure comprehensive care for managers and health professionals as much as for instructors who structure the curriculum is a big task. For the latter, this construction is based on the search of suitable teaching resources to achieve this end.

Currently, we have a significant list of schools in Brazil using active methodologies in partnership with the Primary Health Care (PHC), allowing a broader learning approach. The organization of health services in SUS is allied to these initiatives, constructing care networks and shared practices. It is worth noting the necessary redefinition of the role of the expert in the matrix and in the construction of Singular Therapeutic Projects, next to the Family Health Team, as well as making connections among different levels of care, based on the health care needs to shape lines that ensure longitudinally and access to the health care (Feuerwerker \& Merhy, 2008).

Coherent with this health care approach, it is extremely important the formation of institutional and sectorial networks, since health and education, according to the Brazilian Constitution, has SUS as the coordinator of the formation of human resources in health (art. 200, III and IV), and public services as training field for health teaching and researching (art.27).

From the beginning of the XXI century, policies like Stimulus Program for Curricular Changes in Medical Courses (PROMED), National Program for Reorientation of Vocational Training in Health (Pro-SAÚDE) and the Labor Educa- 
tion Program Health were instigators of change at universities concerning to health professions (Cavalheiro \& Guimarães, 2011). These induce transformation policies in health education providing the central axis of the spread of an active learning model, in which teaching is pushed back to the reality of health care by SUS, strengthening the relationship between teaching and service provision.

However, there is still great resistance and changes are difficult, as in Brazil prevails the model of health training compatible with a previous health care system model (Sisson, 2009).

The Medical Course of the University City of São Paulo in 2004 was one of the first to begin with important curricular innovations, especially in the aspects that refer to Interprofessional Learning in the SUS Service Network. Considering the Brazilian educational and healthcare scenario, this article intends to present and analyze the representations of medical students regarding the experience lived together with the multiprofessional teams of the Family Health Strategy-ESF.

\section{Objective}

The aim of this paper is to describe aspects of the interprofessional work during the learning process of undergraduate medicine students inserted into the reality of the community primary healthcare at a Family Health Unit, analyzing the evaluation and describing their impressions on procedures, relationships and learning.

\section{Methods}

This study has the approval of the Research Ethics Committee-CAAE0115.0.186.000-08 and consisted of a prospective longitudinal study carried on with undergraduate medical students from $1^{\text {st }}$ up to $4^{\text {th }}$ year of the São Paulo City University (UNICID) from 2008 until 2011. The first axis of the teachinglearning process was operationalized through Problem Based Learning (PBL) theory, student-centered and in small groups (Barrows, 1980). The second axis, the Oriented Learning inside Community, has two important aspects: health priorities (based on epidemiological descriptors), and social relevance for each particular community.

The integration program at Family Health Unit, called PISCO (Programa de Integração em Saúde na Comunidade-Integration Program in Community Health), intend to make the students to become accustomed, from the very beginning of their course and along the first four years, with Health Primary Care, as they could be awareness, could experience and could understand the operation of a Family Health Unit. The program aims to achieve its objective through the interaction of students with the Family Health Team, which is the core of primary care, in the municipality of Guarulhos-SP. Thus, students experienced and developed different skills and competences, important to work in Public 
Health. Some powers of this program, concerning to development are: comprehensive approach (existence, gender, culture, personal, family, community); teamwork; coordination amongst levels of care; clinical approach; communication; knowledge management; public health concepts, health promotion, and the management area (management, leadership) (Silva \& Trad, 2005).

PISCO uses problematizing as procedure of learning, working inside reality and identification of concrete problems health professionals jointly with the community, as to produce a participatory solution process. The tutors/teachers come from different careers (psychology, medicine, biomedicine, physics, nursing, dentistry), responding to the identified problems, which usually require a variety of approaches, knowledge and skills, requiring an interaction and, eventually, intersectional action. The problematization of experiences in PISCO is based on the "perception and characterization of families" followed by the students during 4 years (2 families/student/year), as well as "clinical aspects" (diabetes, hypertension, pneumonia, pregnancy, child development) in different family members and/or community. They also address social aspects that interfere with the quality of life of the people of the family (poverty, violence, difficulty in accessing health services) and the context in which they are inserted. The Arch of Maguerez is a resource used in PISCO to systematize the reflections of the practice. In the first axis of the course mentioned in this study, students participate in PBL sessions, where they discuss topics related to PISCO (epidemiologically relevant) and also other cognitive aspects necessary to the level of student training.

Both learning and evaluation processes foresee narratives to do "practical reflection" over the experiences of the work developed in SUS health units. These are built from "situations experienced in the territory", being used in every semester and in all groups. Only one situation in each group was chosen, that one considered of "major significance" by the group to be used for the moment of reflection about practice.

This study conducted a qualitative and quantitative analysis of the narratives about student performance on learning while doing by means of discourse analysis. Each day, each student registered in cards the most relevant impressions on their own activities at the integration program in the SUS network. They were directed by guiding questions like "What are your impressions of the day?" "In relation to what and to whom?" All reports were analyzed through Quali Quanti $\mathrm{Soft}^{\star}$ software, which allows an analysis of the collective subject discourse, according to their social representations (Lefevre \& Lefevre, 2006).

This model adopt the theory of social representations, that "lists and articulates a series of operations on raw data constituted of statements obtained through empirical polling using open-ended questions, what results in collective statements made up of different extracts of individual statements" (Lefevre \& Lefevre, 2003, Lefevre \& Lefevre, 2006). The social representations guide us on the way to name and jointly define the different aspects of atypical reality, so to 
be interpreted (Jodelet, 1993). The constituents of representations are information, images, principles, values, and beliefs, cultural and ideological elements, which in this study represented the impressions of students after learning in service at SUS network.

A total of 1483 cards were distributed, along four years. During the 8 insertion program steps, there was a great decrease in the number of collected cards. To maintain a balance between all the steps and avoid bias in the analysis, the step with fewer cards was used as a parameter to establish the minimum number of cards to be selected in the other stages. Thus, a simple random sample was made and all steps should have a single representative number of 23 cards by each stage and 232 cards as the total sample used for analysis. All cards were sorted by date to allow an accurate analysis of the time they were recorded.

The data were qualitatively analyzed by means of the interpretation of 73 narratives produced during the learning phase and the assessment of learning. The narratives used in this study were chosen in each group of students from different learning course period during four years of data collection. The speeches contained in the narratives were evaluated using content analysis procedure from units of meaning and, later on, grouped into thematic categories (Bardin, 2000). Quantitative analysis consisted in grouping records to consider the impressions, procedures, relationships and learning, reported by students. The relative frequency was calculated with $95 \%$ confidence intervals for each estimated point.

\section{Results and Discussion}

The analysis of the students reports about the everyday activity impressions has drawn the attention to a frequent feeling, motivation, in $51 \%$ of cases $(95 \%, \mathrm{CI}$ $45 \%$ to $58 \%$ ) with a significant difference in relation to others. Such motivation was an important component for the reference of students about learning from experiencing social representations. Categorization displayed records as positive or negative, allowing to identify a significant number of positive feelings (93\%, $95 \%-89 \%$ to $96 \%$ ). Concerning to the Impressions of the day, students indicated the item procedures in $26 \%$ of cases $(95 \%-21 \%$ to $32 \%$ ) when asked About that, and pointed relationships in interprofessional teams in $74 \%(95 \%$ $68 \%$ to $79 \%$ ) when asked From whom?

The speeches of the subjects were analyzed in relation to the social representations of the experiences of medicine undergraduate students about their experience within the scenario of SUS network. After using the Qualiquantisoft software, several themes were identified, highlighting the Work Experience Group and Professional Identification (16\%, 95\% - 12\% to 22\%) compared to the interprofessional approach, that was the focus of analysis of the data according to the purpose of the study. We stress that the speech in relation to this subject may be indirect, or even that interprofessionality is not an issue discussed with students and teachers, not being one of the main focus. Figure 1 shows the distribution of social representations by category. 


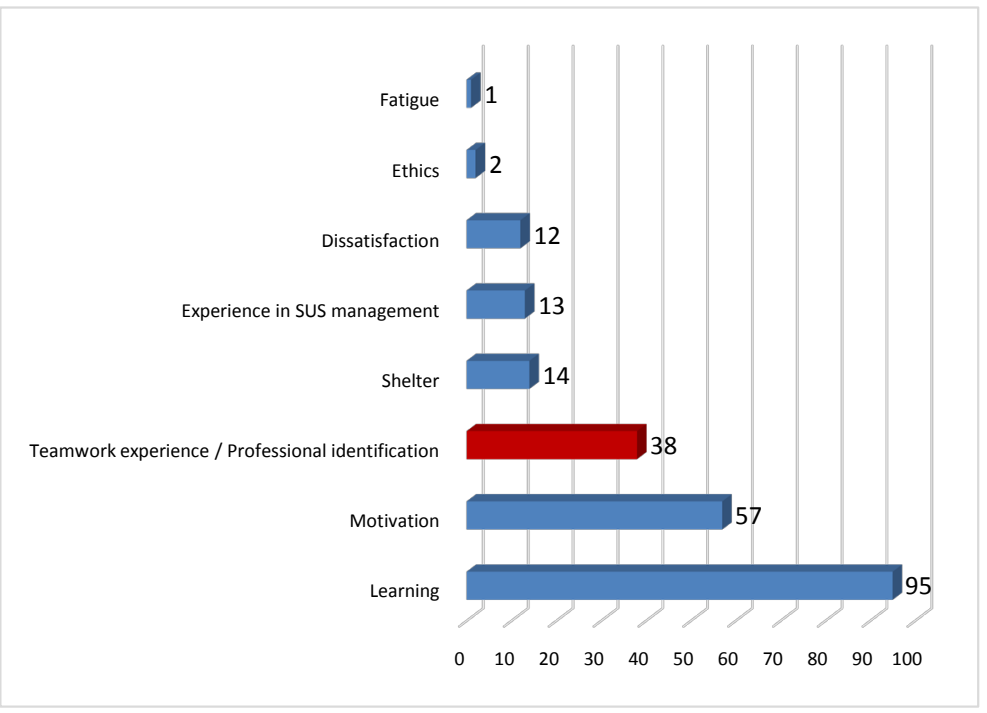

Figure 1. Distribution of Social Representations-"what mobilizes more"medical students experiences at Family Health Teams, 2008-2012.

We observed that the activities were mainly developed by students in the beginning of the medical school rather than by those attending the last years. The experience with nursing was quite intense at times in practice, especially during the nursing consultations during the initial four stages of medical course. It is noteworthy that one of the cards revealed: - be happy to differentiate a medical consultation from a nursing consultation.

Regarding the talking about team activities, they emerged more at the $2^{\text {nd }}$ and $4^{\text {th }}$ stage, when students worked in groups (planning and execution). Generally at the $2^{\text {nd }}$ stage the activity is more focused on the implementation of intervention projects that were derived from the community problems, recognized during the previous six months, and at Step 4. Issues related to Women's Health mobilized students, teachers and other professionals.

The multi professional activities were reported by students in most stages of PISCO, with greater emphasis in even-numbered semesters, when the activities themselves require jointly action as implementing intervention activities, and constructing women and elderly groups in the $4^{\text {th }}$ stage, and obesity in the 6 th stage of the medical course, but still below the professional proportion. We realize that the planning of actions were mentioned, as well as Group Work and Work with Community, the latter in an amount of time close to the laboran Interprofessional Activity, as they require a more collective and shared participation of professionals.

Concerning to the analysis of the narrative, they were built from Situations experienced in the territory, being used in all semesters, with only one chosen by the group and considered as of Major significance for their reflection on practice. The narratives selected by students at each stage were used for the analysis in this study, considering that the experiences at each level of the course are so unique that could warrant the variety of sample. 
Students considered the practical activities at Community as the Most important scenarios ever experienced (35\%), followed by activities at Family Health Unit (23\%), schools and kindergartens (23\%). The other frequencies observed about the experienced scenarios can be observed in Figure 2.

The narratives analysis pointed out the professional and personal influences of the actors belonging to staff, customers, preceptors and his peers in the experiences of the students as important, having been used the thematic category Who impressed more the student in PISCO...

We identified a chief predominance of Community People category, indicating an awareness of students to community people's problems in their context and in relationships. Another significant actor who touched students, reported in $11 \%$ of cases, was the Community Health Agent (95\% - 6\% to 18\%), who is also a community person, but has an essential connection to Family Health Strategy. The physician also stood out as a model for medical students in $27 \%$ of reports (95\% - 19\% to 37\%), being the Doctor-Patient Relationship, the Commitment to family, and the Availability of sharing with Health Team, the key issues identified in the narratives. The nurse was also an important supporter in many situations, being the fourth most frequent category $(6 \%, 95 \%-3 \%$ to 13\%). Other frequencies on who else scored are shown in Figure 3.

The Aspects that influenced the training of medical professionals were analyzed inside the content of the narratives, especially on the competence of Identifying Vulnerability and Risks, to which people in the community are subject to $41 \%$ (95\% - 33\% to $49 \%$ ). There was a strong rise on other aspects, like: the ability to contribute to the improvement of the situation and/or condition of the people of the territory, and the possibility of professional practice, to make a positive or negative example for students in their construction of the professional characteristics. The remaining frequencies of reports on aspects that influence the professional training can be seen in Figure 4.

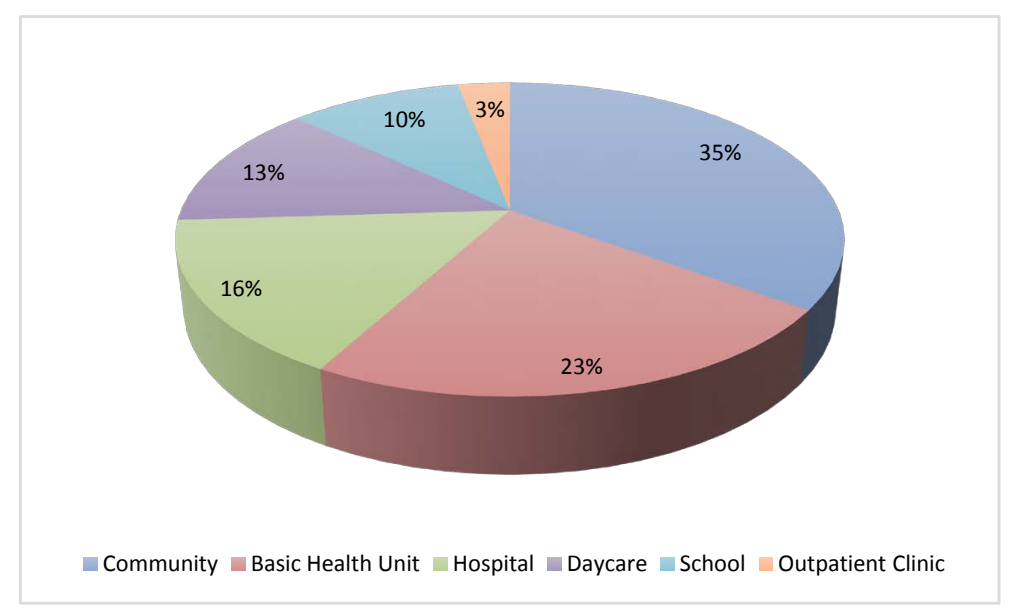

Figure 2. Distribution in order of importance in the community Scenarios referenced by medical students in PISCO, presented in the content analysis narratives. 


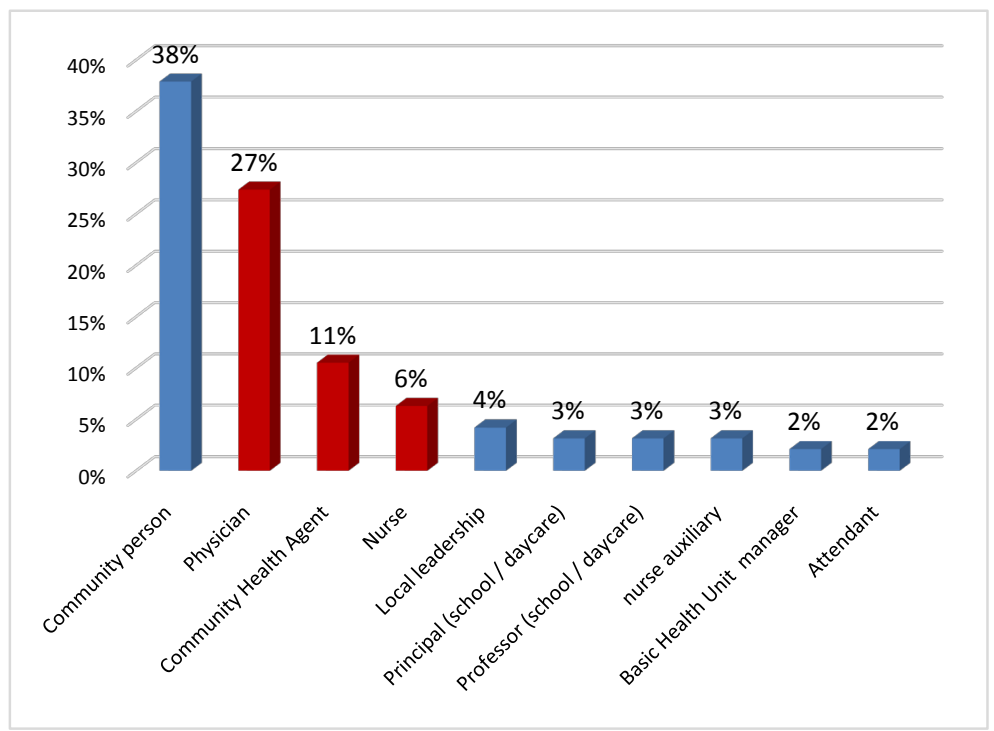

Figure 3. Distribution of the categories appearing in the students speeches Narratives considering "who more marked the student in PISCO".

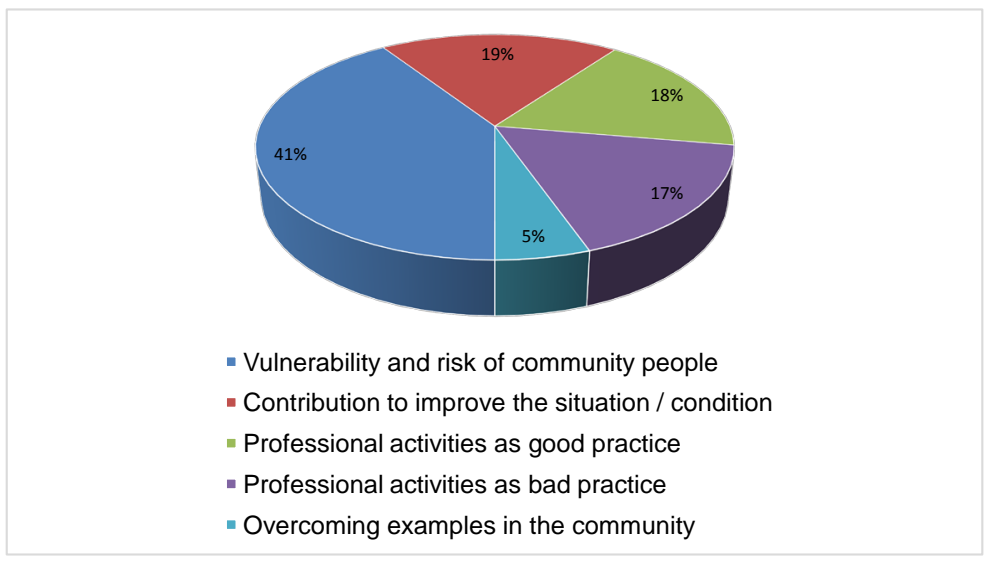

Figure 4. Distribution of the aspects mentioned by the students about the influence of working at Family Health Strategy during their training.

As the records were made at the end of each activity and there was a reduction in the records at each year of the survey, there was a constraint of report representation, since the last stages of the program showed smaller number of cards. We believe that the random sampling method counterbalanced this limitation. The applicability of the data also has limitations considering that the data refer to a long search, but linked to a specific program. We believe that further studies with undergraduate medicine students inserted in similar programs could clear aspects of inter professionality influence on learning process.

\section{Conclusion}

Considering our findings, we observed that the records show five major themes, especially predominating motivation, following the feelings of being learning, being useful, being integrated and obtaining knowledge. Regarding the impres- 
sion of the day on the practices of the students concerning the What and Who, the feelings contained in the speeches are the most positive in nature. The students highlighted their activities in the program team and inter professional relationship instead of procedures only. Professional identification and group experience to identify themselves as motivated learning are important representations for the different stages of the medical course. The actors of greater significance in the representations of the students were the community itself, community agents, medical and nursing staff, in that order of importance. The main influence on the formation, recognized by the students, was the development of skills to identify vulnerabilities and risks in the community, as well as both positive and negative role models.

During the analysis of the narratives of the students about the practices in the program, some feelings were identified, like perceptions on What and Who had influenced their training. The most important aspects were shared planning, the construction of therapeutic projects, leadership, patient care and responsibility, teamwork, professional examples and situations and people who impressed the students on the way. Students identify their representations in all these aspects aforesaid, with greater emphasis on teamwork and interprofessional relationships. People in the community were the ones that most influenced the students, followed by the physician. The role of community health agent was essential to bring together students and community.

The data obtained (Figures 1-4) show that the students identify important aspects of Interprofessional Learning that allow the establishment of a Collaborative Practice and of quality to health services that allow students and health teams to important points: developing different skills, better communication between professionals and also with users, strengthening ethics and respect, improving teamwork, strengthening negotiation capacity and shared decision-making, better resource management, and better results of this integration. Both Medical DCNs in Brazil, from 2001 and 2014, include all of these points listed above (Brasil. Ministério da Educação-MS, 2001).

From the speeches of students, we can consider that the integration programs like the rated, outline a positive approach in training human resources for health directed to public health policies. We believe that colleges and universities with similar programs are exerting their social role, as indicated by the speeches of the students, and that we are approaching the federal curricular guidelines of medicine and forming more suitable professional taking into account the needs of SUS.

\section{References}

Bardin, L. (2000). Análise de conteúdo. [Content Analysis.] Lisboa, Portugal: Edições 70.

Barr, H. (1998). Competent to Collaborate; towards a Competency-Based Model for Interprofessional Education. Journal of Interprofessional Care, 12, 181-188.

https://doi.org/10.3109/13561829809014104 
Barrows, H. S., \& Tamblyn, R. M. (1980). Problem-Based Learning: An Approach To Medical Education. New York: Springer.

Batista, N. A. (2012). Educação Interprofissional em Saúde: Concepções e Práticas. [Interprofessional Health Education: Conceptions and Practices.] Caderno FNEPAS, 2, 25-28.

Brasil. Ministério da Educação-MS (2001). Conselho Nacional de Educação. Câmara de Educação Superior. Resolução n.4, CNE/CES de 7/11/2001. Institui diretrizes curriculares nacionais do curso de graduação em medicina-DCNs. [Brazil. Ministry of Education. National Council of Education. Higher Education Chamber. Resolution n.4, CNE/CES of November 7, 2001. Institutes National Curricular Guidelines for Medicine Graduation.J Diário Oficial da União. Brasília, 9 nov. 2001; Seção 1, p. 38.

Brasil. Ministério da Saúde (2000). 11 a Conferência Nacional de Saúde-CNS. Relatório Final. [Brazil. Ministry of Health. 11th National Health Conference. Final Report.] Brasília, DF, 15 a 19 de dezembro de 2000.

Cavalheiro, M. T. P., \& Guimarães, A. L. (2011). Formação para o SUS e os desafios da integração Ensino Serviço. [Training for SUS and the Challenges of Integration Education Service.] Caderno FNEPAS, 1, 19-27.

Ceccim, R. B., \& Feuerwerker, L. C. M. (2004). O quadrilátero da formação para a área de saúde: ensino, gestão, atenção e controle social. [The Quadrilateral of Training for Health Zone: Teaching, Administration, Attention and Social Control.] PHYSIS Revista Saúde Coletiva, 14, 41-66.

Feuerwerker, L. C. M., \& Merhy, E. E. (2008). A contribuição da atenção domiciliar para a configuração de redes substitutivas de saúde: desinstitucionalização e transformação de práticas. [The Contribution of Home Care to the Configuration of Substitutive Health Networks: Deinstitutionalization and Practice Transformation.] Rev PanamSaludPublica., 24, 180-188. https://doi.org/10.1590/S1020-49892008000900004

Jodelet, D. (1993). Représentationssociales: Un domaineen expansion. [Social Representations: An Expanding Field.] In D. Jodelet (Ed.) Les représentationssociales. Paris: PUF, 1989, 31-61. Tradução: Tarso Bonilha Mazzotti. Revisão Técnica: Alda Judith Alves-Mazzotti. UFRJ-Faculdade de Educação, dez.

Lefevre, F., \& Lefevre, A. M. C. (2003). O discurso do sujeito coletivo: Um novo enfoque em pesquisa qualitativa. [The Collectivesubject Speech: A New Approach in Qualitative Research.] Caxias do Sul: Educs. (Desdobramentos)

Lefevre, F., \& Lefevre, A. M. C. (2006). O sujeito coletivo que fala. [The Collective Subject Speaks.] Interface Comunicação, Saúde, Educação, 10, 517-524.

Machado, J. L. M., Machado, V. P. M., \& Vieira, J. E. (2012). How to Progress from Discourse to Practice? A New Agenda for Change in Medical Schools into the Next Decade. Creative Education, 3, 595-599.

McNair, R. P. (2005). The Case for Educating Health Care Students in Professionalism as the Core Content of Interprofessional Education. Medical Education, 39, 456-464.

Silva, I. Z. Q. J., \& Trad, L. A. B. (2005). O trabalho em equipe no PSF: Investigando a articulação técnica e a interação entre os profissionais. [Teamwork in the PSF: Investigating the Technical Articulation and Interaction among Professionals.] Interface Comunicação, Saúde, Educação, 9, 25-38.

Sisson, M. C. (2009). Identidades profissionais na implantação de novas práticas assistenciais. [Professional Identities in the Accomplishment of New Care Practices.] Revista Brasileira de Educação Médica, 33, 116-122.

WHO Organização Mundial de Saúde (2010). Marco para Ação em Educação 
Interprofissional e Prática Colaborativa-Redes de Profissôes de Saúde Enfermagem e Obstetrícia Recursos Humanos para a Saúde. [Framework for Action in Interprofessional Education and Collaborative Practice-Health Professions Networks for Nursing and Obstetrics Human Resources for Health.] 